\title{
Multi-variable experimental data set of agronomic data and gaseous soil emissions from maize, oilseed rape and other energy crops at eight sites in Germany
}

Janine Mallast ${ }^{1 *}$, Heinz Stichnothe ${ }^{1}$, Heinz Flessa ${ }^{2}$, Roland Fuß ${ }^{2}$, Antje M. Lucas-Moffat ${ }^{2}$, Ute PetersenSchlapkohl ${ }^{2,3}$, Jürgen Augustin ${ }^{4}$, Ulrike Hagemann ${ }^{4}$, Katharina Kesenheimer ${ }^{5}$, Reiner Ruser ${ }^{5}$, Teresa Suárez Quiñones ${ }^{6}$, Annette Prochnow' ${ }^{6}$, Klaus Dittert ${ }^{7}$, Sarah Koebke ${ }^{7}$, Vytas Huth ${ }^{8}$, Stephan Glatzel ${ }^{9}$, Thomas Räbiger ${ }^{10}$, Astrid Knieß ${ }^{10}$, Henning Kage ${ }^{10}$, Hannes Hegewald ${ }^{11}$, Olaf Christen ${ }^{11}$

1 Thuenen Institute of Agricultural Technology, Braunschweig, Germany

2 Thuenen Institute of Climate-Smart Agriculture, Braunschweig, Germany

${ }^{3}$ Thuenen Institute of Biodiversity, Braunschweig, Germany

${ }^{4}$ Leibniz Centre for Agricultural Landscape Research (ZALF), Muencheberg, Germany

${ }^{5}$ Institute of Crop Science, Department Fertilization and Soil Matter Dynamics, University of Hohenheim (340i), Stuttgart, Germany

${ }^{6}$ Leibniz Institute for Agricultural Engineering and Bioeconomy, Potsdam-Bornim, Germany

7 Department of Crop Sciences - Division of Plant Nutrition and Crop Physiology, University of Goettingen, Germany

${ }^{8}$ Landscape Ecology, Faculty of Agricultural and Environmental Sciences, University of Rostock, Germany

9 Department of Geography and Regional Research, University of Vienna, Austria

10 Institute of Crop Science and Plant Breeding, Christian-Albrechts-University, Kiel, Germany

${ }^{11}$ Institute of Agricultural and Nutritional Science, Martin-Luther-University Halle-Wittenberg, Germany

*e-mail: janine.mallast@thuenen.de

Abstract: Greenhouse gas (GHG) emissions as well as other gaseous emissions and agronomic variables were measured for three years $(2011 / 2012-2014 / 2015)$ at eight experimental field sites in Germany. All management activities were consistently documented. The database (GHG-DB-Thuenen) stores these multi-variable data sets of gas fluxes $\left(\mathrm{CO}_{2}, \mathrm{~N}_{2} \mathrm{O}, \mathrm{CH}_{4}\right.$ and $\left.\mathrm{NH}_{3}\right)$, crop parameters (ontogenesis, aboveground biomass, grain and straw yield, $\mathrm{N}$ and $\mathrm{C}$ content, etc.), soil characteristics (nitrogen content, $\mathrm{NH}_{4}-\mathrm{N}, \mathrm{NO}_{3}-\mathrm{N}$, bulk density etc.), continuously recorded meteorological variables (air and soil temperatures, radiation, precipitation, etc.), management activities (sowing, harvest, soil tillage, fertilization, etc.), and their metadata (methods, further information about variables, etc.). In addition, $\mathrm{N}_{2}$ data were measured and analyzed. Site-specific calculated $\mathrm{C}$ and $\mathrm{N}$ balances for the respective crops and crop sequences are also available.

Keywords: greenhouse gas emissions, maize, oilseed rape, energy crops, field experiment data.

1 INTRODUCTION AND ORIGINAL PURPOSE: GHG-DB-Thuenen was developed to store and archive a multi-variable data set of two research projects - "Potentials for the mitigation of greenhouse gas emissions from energy crop cultivation for biogas production" (hereafter BGD project) and "Mitigation of greenhouse gas emissions in oilseed rape cropping with particular consideration of nitrogen fertilization" (hereafter OSR project). This database allows flexible data processing and analyses with different disciplinary and interdisciplinary backgrounds.

The original purpose of both collaborative projects was to quantify and to evaluate greenhouse gas (GHG) emissions for oilseed rape, maize and other energy crops, considering that oilseed rape is a major renewable resource for biodiesel and that maize plays a key role as feedstock for biogas production in Germany.

Various weekly and event-related measurements of gaseous emissions were conducted. The closed dynamic chamber method was used to measure $\mathrm{CO}_{2}$ fluxes (Hoffmann et al. 2015), while $\mathrm{CH}_{4}$ and $\mathrm{N}_{2} \mathrm{O}$ were measured using static closed chambers (modified based on Hutchinson \& Mosier 1981, Parkin \& Venterea 2010, de Klein \& Harvey 2015). The same measuring technique and methods were used at all experimental sites. The field flux measurements are described in detail by Ruser et al. (2017).

Emissions of $\mathrm{NH}_{3}$ after fertilization were recorded using the Dräger tube method (Pacholski et al. 2006). Meteorological parameters such as air and soil temperature, precipitation, wind speed and direction as 
well as relative air humidity were continuously recorded at automated meteorological stations at each field site. All management activities at the field sites were documented. Measured soil characteristics include e.g. soil texture, $\mathrm{NH}_{4}-\mathrm{N}, \mathrm{NO}_{3}-\mathrm{N}$, bulk density, $\mathrm{pH}$ value, nitrogen and carbon content. Crop parameters such as ontogenesis, aboveground biomass, grain and straw yield, carbon and nitrogen content were measured to supplement the GHG measurements. All crop and soil properties were sampled with documented standard methods. The composition of the used digestate (e.g. total nitrogen content, $\mathrm{NH}_{4}-\mathrm{N}$, organic carbon) were also analyzed. Additionally, $\mathrm{N}_{2}$ data were measured in complementary laboratory incubation experiments. More details about the sampling intervals can be found in the database documentation (see supplementary material).

Some results from both projects have already been published, e.g. Fiedler et al. 2015, Fiedler et al. 2016, Fiedler et al. 2017, Heintze et al. 2017, Hoffmann et al. 2018, Huth et al. 2017, Lucas-Moffat et al. 2018, Peter et al. 2016, Pohl et al. 2015, Ruser et al. 2017. Further information is provided in the final project reports (only in German).

The database with the multi-variable data set is stored in the OpenAgrar repository and is publicly via OpenAgrar (Mallast et al. 2018, https://dx.doi.org/10.3220/DATA20180201-080050).

2 SITES, FIELD EXPERIMENTS AND THEIR DESIGNS: The BGD and the OSR project each consist of five sites located throughout Germany. Two of these sites, Dedelow and Hohenschulen, are part of both projects, resulting in eight different field sites (see Figure 1). The main climate and soil characteristics of each field site as well as the respective project affiliation are shown in Table 1.

Figure 1. Map of experimental sites - OSR project represented by squares and triangles; BGD project embodied by circles and triangles

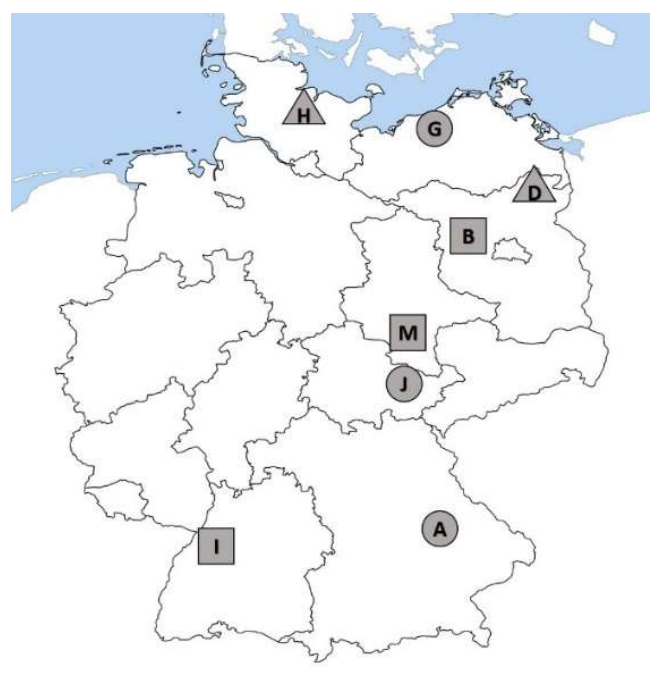

\begin{tabular}{|c|c|c|c|c|c|c|c|c|c|}
\hline \multirow[t]{2}{*}{ Project } & \multirow[t]{2}{*}{ Site } & \multirow{2}{*}{$\begin{array}{l}\text { Lati- } \\
\text { tude }\end{array}$} & \multirow{2}{*}{$\begin{array}{l}\text { Longi Air } \\
\text {-tude temp. }\end{array}$} & \multirow{2}{*}{$\begin{array}{l}\text { Precipi- } \\
\text { tation }\end{array}$} & \multirow[t]{2}{*}{ Soil type } & \multicolumn{3}{|c|}{ Soil texture (\%) } & \multirow[t]{2}{*}{$\mathrm{pH}$} \\
\hline & & & & & & sand & silt & clay & \\
\hline BGD & Ascha (A) & 48.99 & 12.66 & $7.5^{\circ} \mathrm{C} 807 \mathrm{~mm}$ & Cambisol & 55 & 31 & 14 & 6.2 \\
\hline OSR & $\begin{array}{l}\text { Berge (B) } \\
\text { (Bornim) }\end{array}$ & 52.62 & 12.78 & $8.7^{\circ} \mathrm{C} 503 \mathrm{~mm}$ & Luvisol & 75 & 19 & 6 & 6.6 \\
\hline BGD \& O & Dedelow (D) & 53.38 & 13.79 & $8.4^{\circ} \mathrm{C} 485 \mathrm{~mm}$ & Luvisol & 59 & 31 & 10 & 6.8 \\
\hline BGD & $\begin{array}{l}\text { Dornburg }(\mathrm{J}) \\
\text { (Jena) }\end{array}$ & 51.00 & 11.66 & $8.8^{\circ} \mathrm{C} 596 \mathrm{~mm}$ & Haplic Luvisol & 3 & 72 & 25 & 7.1 \\
\hline BGD & Gülzow (G) & 53.81 & 12.07 & $8.4^{\circ} \mathrm{C} 559 \mathrm{~mm}$ & Stagnic Luvisol & 69 & 23 & 8 & 6.6 \\
\hline BGD \& O & Hohenschuler & 54.31 & 9.99 & $8.9^{\circ} \mathrm{C} 732 \mathrm{~mm}$ & $\begin{array}{l}\text { Haplic } \\
\text { Luvisol/Anthrosol }\end{array}$ & 60 & 29 & 11 & 6.7 \\
\hline OSR & $\begin{array}{l}\text { Ihinger Hof (I) } \\
\text { (Hohenheim) }\end{array}$ & 48.74 & 8.92 & $8.3^{\circ} \mathrm{C} 688 \mathrm{~mm}$ & Haplic Luvisol & 3 & 78 & 19 & 7.1 \\
\hline OSR & Merbitz (M) & 51.62 & 11.91 & $9.0^{\circ} \mathrm{C} 520 \mathrm{~mm}$ & Haplic Chernosem & 16 & 68 & 16 & 7.4 \\
\hline
\end{tabular}


The experiments of both projects and their designs are not identical and therefore described separately below.

2.1 THE BGD PROJECT: It is a satellite project of the long-term (2005-2015) EVA project "Development and comparison of optimized cultivation systems for the agricultural production of energy crops under different site conditions in Germany"1 and uses five of the EVA project sites. Starting in 2011, the BGD project worked on two distinct EVA experiments: the Small and the Large digestate experiment ${ }^{2}$.

The Small digestate experiment studies one of the EVA energy crop sequences under three different $\mathrm{N}$-fertilizer and digestate treatments: $100 \%$ biogas digestate, $100 \%$ mineral nitrogen fertilizer as well as $50 \%$ digestate $+50 \%$ mineral nitrogen fertilizer. Digestate was applied using a band spreader with a trailing hose (except Gülzow ${ }^{3}$ ). The basis crop sequence consisted of energy maize (Zea mays L.), winter wheat (Triticum aestivum L.), white mustard (Sinapis alba L. - sown as catch crop), energy maize (Zea mays L.), winter rye used as WPS ${ }^{4}$ (Secale cereale L.), sorghum (depending on the site and the regional climatic conditions, either Sorghum bicolor L. MOENCH or Sorghum $\times$ drummondii). The replicated crop sequence with a temporal offset of one year was enhanced by winter triticale ( $\times$ Triticosecale Wittmack) and ryegrass (Lolium perenne L.) (details in Figure 2).

\begin{tabular}{|c|c|c|c|c|c|c|c|}
\hline \multirow{8}{*}{ 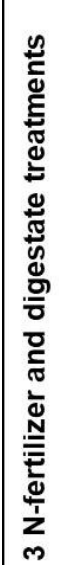 } & \multirow{3}{*}{$\begin{array}{l}100 \% \text { biogas } \\
\text { digestate }\end{array}$} & & & & \multicolumn{3}{|c|}{1 basic crop sequence with 2 replicates } \\
\hline & & Maize & Winter wheat & Mustard/ fallow & Maize & Winter rye & Sorghum \\
\hline & & Sorghum & Winter triticale & Rye grass & Winter wheat & Mustard/ fallow & Maize \\
\hline & \multirow{3}{*}{ 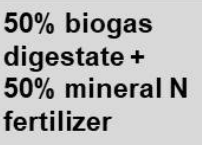 } & & & & & & \\
\hline & & Malze & WVinter wheat & Mustard/ tallow & Malze & VVInter rye & sorghum \\
\hline & & Sorghum & Winter triticale & Rye grass & Winter wheat & Mustard/ fallow & Maize \\
\hline & \multirow{2}{*}{$\begin{array}{l}100 \% \text { mineral } N \\
\text { fertilizer }\end{array}$} & Maize & Winter wheat & Mustard/ fallow & Maize & Winter rye & Sorghum \\
\hline & & Sorghum & Winter triticale & Rye grass & Winter wheat & Mustard/ fallow & Maize \\
\hline
\end{tabular}

The Large digestate experiment was designed as an energy maize monoculture with graded biogas digestate amendments and mineral fertilizer (50\% digestate, $75 \%$ digestate, $100 \%$ digestate, $125 \%$ digestate, $200 \%$ digestate, $0 \%$ mineral $\mathrm{N}$ as control and $100 \%$ mineral $\mathrm{N}$ ) at all sites. In contrast to the Small digestate experiment and the OSR project experiment, at each site all seven measuring plots changed their location every year to eliminate $\mathrm{N}$ effects from the previous year.

For both experiments in the BGD project, absolute quantities of mineral fertilizer (calcium ammonium nitrate - CAN) were calculated relatively to site-specific levels of $100 \% \mathrm{~N}$ fertilization. The $\mathrm{N}$ content of the used biogas digestate and a mineral fertilizer equivalent of $70 \%$ determined the applied amount of digestate.

2.2 THE OSR PROJECT: It was established in 2012. The experimental design comprises a uniform field trial with an identical crop sequence consisting of oilseed rape (Brassica napus $L$.) - winter wheat (Triticum aestivum L.) - winter barley (Hordeum vulgare $L$.) cultivated at a randomized split-plot design with four replicated blocks (Error! Reference source not found.) and nine fertilizer treatments. Seven of those concern oilseed rape only. Of those, four treatments belong to the intensive monitoring program to analyze and to evaluate $\mathrm{N}_{2} \mathrm{O}$ and $\mathrm{CH}_{4}$ fluxes ${ }^{5}$ : (N3) - reduced mineral $\mathrm{N}$-fertilization with $120 \mathrm{~kg} \mathrm{~N} / \mathrm{ha}$, (N4) - mineral $\mathrm{N}$-fertilization with $180 \mathrm{~kg} \mathrm{~N} / \mathrm{ha}$ (best management practice treatment), (N6) - full replacement of mineral $\mathrm{N}$-fertilizer by digestate, and (N7) - full replacement of mineral $\mathrm{N}$-fertilizer by

\footnotetext{
${ }^{1}$ https://energiepflanzen.fnr.de/projekte/anbau/eva/? _ mstto=en

${ }^{2}$ Experiment names are agreed among all project partners and are used in the associated database.

${ }^{3}$ Injection technique was used

${ }^{4}$ WPS - whole plant used as silage

${ }^{5}$ Additional $\mathrm{N}_{2} \mathrm{O}$ and $\mathrm{CH}_{4}$ fluxes was analyzed and evaluated for treatment $\mathrm{N} 1$ and $\mathrm{N} 5$ in some sites and some years: Berge from 2015 to 2016 (N5), Dedelow from 2013 to 2016 (N1) and from 2014 to 2016 (N5), Hohenschulen from 2013 to 2014 (N1) and from 2015 to 2016 (N5), Ihinger Hof from 2014 to 2016 (N5), Merbitz from 2013 to 2016 (N1) and from 2014 to 2016 (N5).
} 
digestate with nitrification inhibitor (Piadin). The trailing hose technique was used to apply the digestates as in the BDG-project. Three additional treatments were established to analyze the site-specific yield optimum (N1) - No N fertilization as control, (N2) - reduced mineral N-fertilization with $60 \mathrm{~kg} \mathrm{~N} / \mathrm{ha}$, (N5) - high mineral $\mathrm{N}$-fertilization with $240 \mathrm{~kg} \mathrm{~N} / \mathrm{ha}$ ). For winter wheat and winter barley a site-specific Nfertilization according to best agricultural management practices was applied. As a second control, a long-term grassland without fertilization and management was also monitored.

Figure 3. Spatial scheme of the experimental design of the OSR project (exemplary for one year at one field site, each year crops rotate within each block)

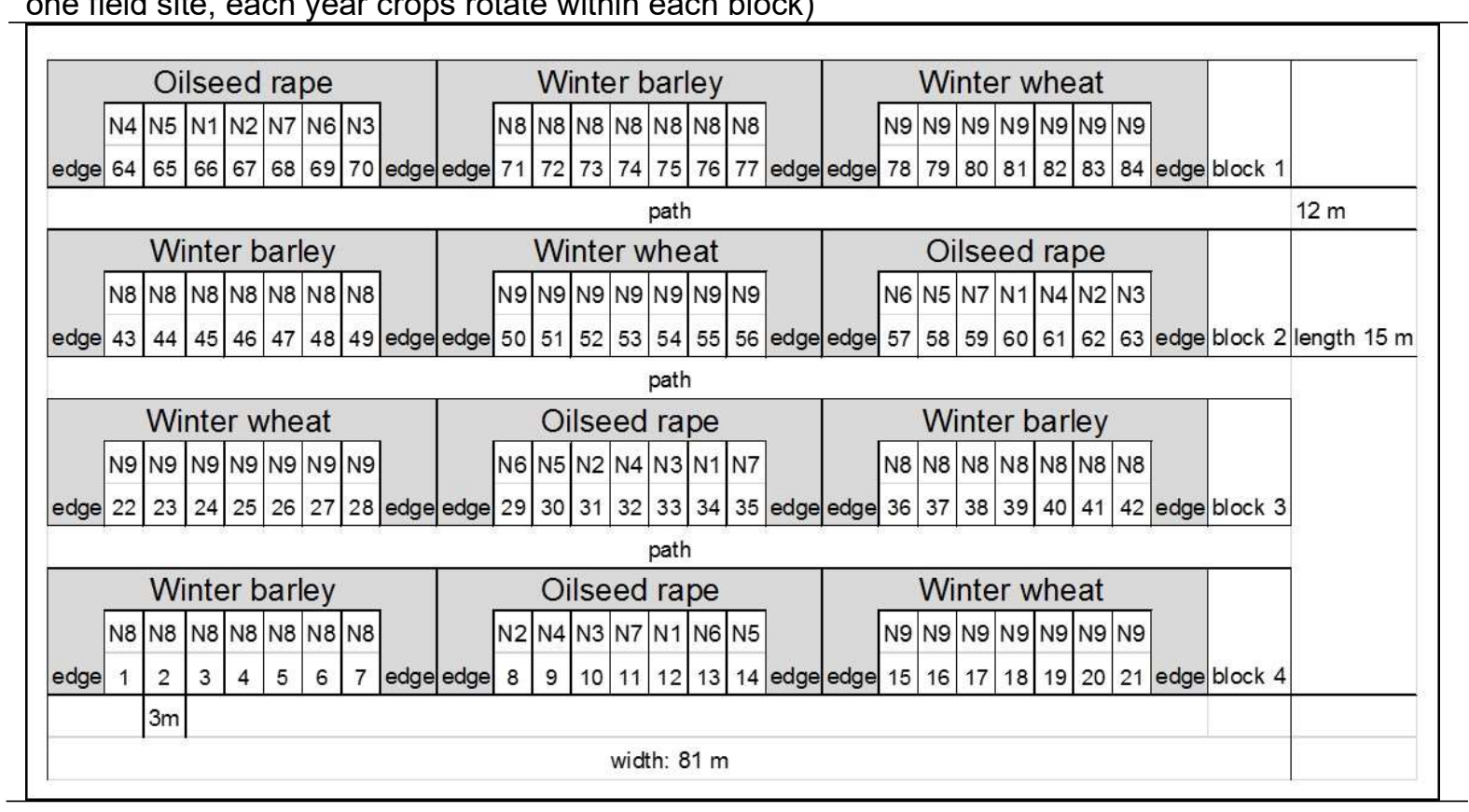

3 DATABASE STRUCTURE AND DATA ACCESS: GHG-DB-Thuenen was developed with Microsoft Access Database 2007-2016. The database provides a combination of a large base of data (in total 43 million records) spread over 48 separate tables (see Table 2). All tables are sorted into six data categories: "experimental design", "driving forces", "measurements - raw data", "measurements processed data", "specific statistics" and "metadata".

\begin{tabular}{lll}
\hline Table 2. All tables of the GHG-DB-Thuenen & \\
\hline Table name & Category & Project \\
\hline D_Management & Driving forces & BGD \& OSR \\
\hline D_Meteo & Driving forces & BGD \& OSR \\
\hline D_Soilprofile & Driving forces & BGD \\
\hline E_Block & Experimental design & BGD \& OSR \\
\hline E_Crop & Experimental design & BGD \& OSR \\
\hline E_Experiment & Experimental design & BGD \& OSR \\
\hline E_Plot & Experimental design & BGD \& OSR \\
\hline E_Site & Experimental design & BGD \& OSR \\
\hline E_Treatment & Experimental design & BGD \& OSR \\
\hline E_Variation & Experimental design & BGD \& OSR \\
\hline M_Below_LOQ_info & Metadata & BGD \& OSR \\
\hline M_Digestate_info & Metadata & BGD \\
\hline M_EVA_Code_ListA_B & Metadata & BGD \\
\hline M_EVA_Code_ListC & Metadata & BGD \\
\hline M_EVA_Code_ListD & Metadata & BGD \\
\hline M_Experiment_info & Metadata & BGD \& OSR \\
\hline M_Fertilisation_info & Metadata & BGD
\end{tabular}




\begin{tabular}{lll}
\hline Table 2. All tables of the GHG-DB-Thuenen - Continued & \\
\hline Table name & Category & Project \\
\hline M_Information & Metadata & BGD \& OSR \\
\hline M_Installations_info & Metadata & BGD \& OSR \\
\hline M_Management_past & Metadata & OSR \\
\hline M_Methods & Metadata & BGD \& OSR \\
\hline M_Site_info & Metadata & BGD \& OSR \\
\hline M_Soilprofile_info & Metadata & BGD \\
\hline M_Units & Metadata & BGD \& OSR \\
\hline M_Variables & Metadata & BGD \& OSR \\
\hline M_Variable_info & Metadata & BGD \& OSR \\
\hline P_Balances & Processed data - Measurements & BGD \\
\hline P_Emis_CO2_flux & Processed data - Measurements & BGD \& OSR \\
\hline P_Emis_N2O_CH4_daily & Processed data - Measurements & BGD \\
\hline P_Emis_N2O_CH4_flux & Processed data - Measurements & BGD \& OSR \\
\hline P_Emis_NH3_flux & Processed data - Measurements & BGD \& OSR \\
\hline P_Modelled_CO2 & Processed data - Measurements & BGD \& OSR \\
\hline P_Modelled_NO3 & Processed data - Measurements & BGD \& OSR \\
\hline P_NO3leaching & Processed data - Measurements & BGD \\
\hline P_Parameter_CO2 & Processed data - Measurements & BGD \& OSR \\
\hline R_Cl_Tracer & Raw data - Measurements & BGD \\
\hline R_Cl_Tracer_factor & Raw data - Measurements & BGD \\
\hline R_Digestate & Raw data - Measurements & BGD \& OSR \\
\hline R_Emis_CO2_conc & Raw data - Measurements & BGD \\
\hline R_Emis_N2O_CH4_CO2_conc & Raw data - Measurements & BGD \& OSR \\
\hline R_Incubation & Raw data - Measurements & BGD \\
\hline R_Plant & Raw data - Measurements & BGD \& OSR \\
\hline R_Soil_continuous & Raw data - Measurements & OSR \\
\hline R_Soil_periodic & Raw data - Measurements & BGD \& OSR \\
\hline S_Statistics_Balances & Specific statistics & BGD \\
\hline S_Statistics_N2O_flux & Specific statistics & OSR \\
\hline S_Statistics_CO2_flux & Specific statistics & BGD \\
\hline S_Statistics_N2O_CH4_flux & Specific statistics & BGD \\
\hline & & \\
\hline
\end{tabular}

Figure 4. Data structure of the database GHG-DB-Thuenen

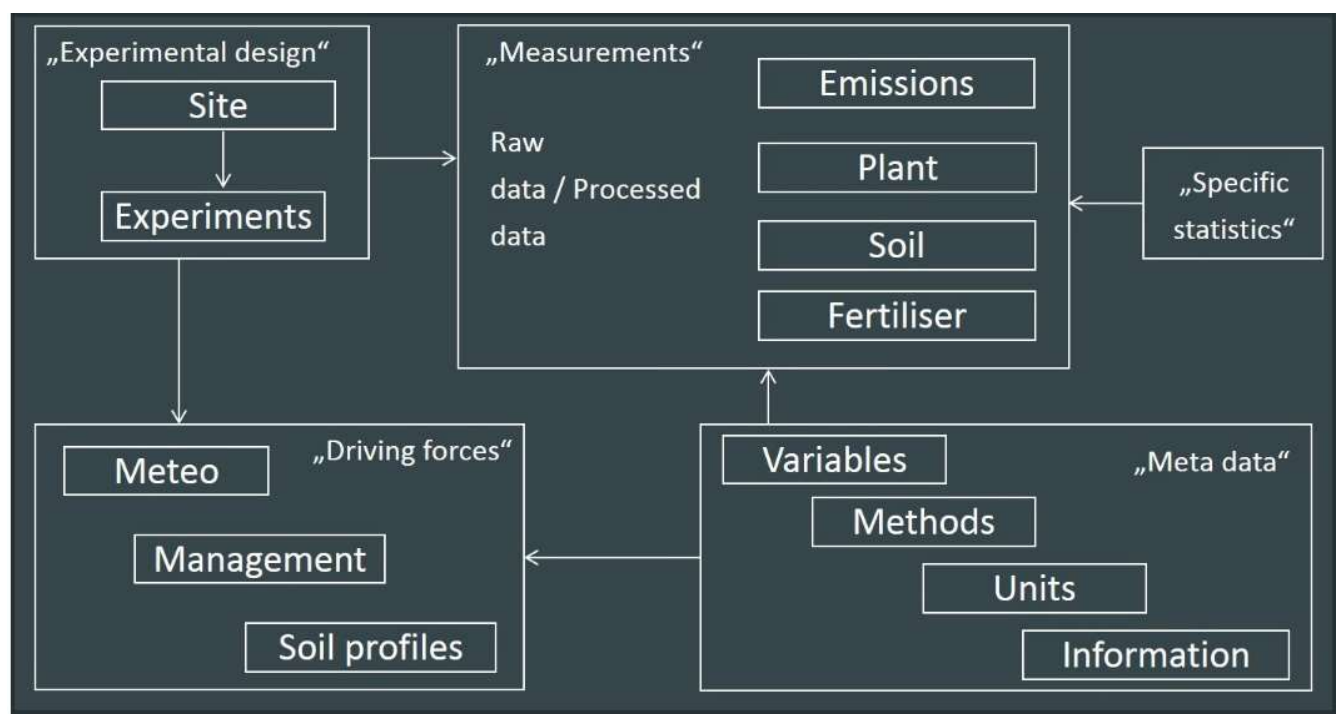


Figure 4 illustrates the simplified data structure. The detailed structure of the data model is provided as a supplement. More details about the database are provided in the documentation (see supplementary material). In January 2021 the database GHG-DB-Thuenen with the research data will become freely available for (re)use by others at the publication server and data repository OpenAgrar (doi: 10.3220/DATA20180201-080050).

3.1 CATEGORY - EXPERIMENTAL DESIGN: The category "experimental design" contains the basic information ("key of the database"). The table "Plot" represents the organizing principle of the database and contains a Plot_ID (the primary key) describing the unique positioning or affiliation of each measured value and the associated information of the database. For each "Measurements" table in the GHG-DB-Thuenen (with the exception of the tables "Meteo" and "Soil profile") there is a 1:n relation to the table Plot. This means that the tables are linked by the foreign key Plot_ID.

3.2 CATEGORY - DRIVING FORCES: This table contains mandatory data on management events such as emergence, sowing, harvest with crop name, soil tillage with soil depth and type, applications of mineral and organic fertilization (including total amount of fertilizer and quantity of $\mathrm{N}$-input from the fertilizer) as well as crop protection. Additionally, dates of crop development, damages, irrigation (amount of applied water), mowing and freeze-kill (catch crops) as well as nutrition supply and previous crop are integrated in this table.

The table "Soil profile" contains general soil parameters to characterize the composition of soil horizons at each field site. All meteorological parameters (see Table 3) were collected as hourly values (daily values for precipitation) in the OSR project and half-hourly values in the BGD project at each field site.

\begin{tabular}{|c|c|c|c|}
\hline Meteorological parameters & Unit & Sampling in/at & Project \\
\hline Air humidity & $\%$ & & BGD \& OSR \\
\hline Air pressure & $\mathrm{hPa}$ & & BGD \\
\hline Air temperature & ${ }^{\circ} \mathrm{C}$ & $200 \mathrm{~cm}$ height & BGD \& OSR \\
\hline Air temperature & ${ }^{\circ} \mathrm{C}$ & $20 \mathrm{~cm}$ height & BGD \\
\hline Global radiation & $\mathrm{W} / \mathrm{m} 2$ & & OSR \\
\hline Photosynth. active radiation & $\mu \mathrm{mol} /\left(\mathrm{m}^{2 *} \mathrm{~s}\right)$ & & BGD \\
\hline Precipitation & $\mathrm{mm} ; \mathrm{mm} / 30 \mathrm{~min}$ & & BGD \& OSR \\
\hline Soil moisture & $\%$ & $10 \mathrm{~cm}$ soil depth & BGD \\
\hline Soil temperature & ${ }^{\circ} \mathrm{C}$ & $2 \mathrm{~cm}$ soil depth & BGD \\
\hline Soil temperature & ${ }^{\circ} \mathrm{C}$ & 5 and $10 \mathrm{~cm}$ soil depth & BGD \& OSR \\
\hline Soil temperature & ${ }^{\circ} \mathrm{C}$ & $20 \mathrm{~cm}$ soil depth & BGD (three sites) \\
\hline Sunshine duration & $\mathrm{h}$ & & OSR (one site) \\
\hline Wind direction & $\circ$ & & BGD \& OSR \\
\hline Wind speed & $\mathrm{m} / \mathrm{s}$ & $200 \mathrm{~cm}$ height & BGD \& OSR \\
\hline
\end{tabular}

3.3 CATEGORY - MEASUREMENTS: All "Measurements" tables follow a similar structure, i.e. the following eight columns are always present and can be complemented by more columns if necessary: Plot_ID: Unique spatial positioning / affiliation of the measured value

Date_or Timestamp_: Point in time of the measured value as date (dd.mm.yyyy) or timestamp (dd.mm.yyyy hh:mm:ss)

Variable_ID: Index of the measured variable

Value : The measured value

Unit_ID: Index of the unit in which the measured value was recorded

Method ID:

Comments: Index of the applied methods of the measured value ID: Comment(s) Unique counter / index of the table

The metadata tables "Variables", "Units" and "Methods" are always linked to each "Measurements" table. Please note that not all measurements are available across all eight field sites.

3.3.1 Crop, soil and fertilizer data: At all experimental sites event-related plant and soil samples were collected. Soil samples for the analysis of $\mathrm{NH}_{4}{ }^{+}$and $\mathrm{NO}_{3}{ }^{-}$contents were taken "parallel" to the gas flux measurements, i.e. each weekly gas flux measurement campaign has a related $\mathrm{NH}_{4}{ }^{+}$and $\mathrm{NO}_{3}{ }^{-}$content. 
Additionally, the composition of the digestate was also analyzed and stored. All measured variables are provided in the supplementary material. The tables "Plant" and "Soil_periodic" are additionally equipped with two Boolean columns (switching variable). The Boolean column "Aggregated" indicates whether a measured value was aggregated based on several values or not. "Inherited" as a second Boolean shows whether a measured value was adopted from another plot or not. If a value was adopted, a comment states from which plot. A further Boolean column "Below_LOQ" in the tables "Soil_periodic" and "Digestate" displays whether a measured value is below the limit of quantification (LOQ) or not. The tables "Cl_tracer" and "Cl_tracer_factor" contain data sets of additional field experiments to quantify $\mathrm{NO}_{3}{ }^{-}$in soil. $\overline{\mathrm{A}}$ further additional laboratory experiment quantified $\mathrm{N}_{2}, \mathrm{~N}_{2} \mathrm{O}, \mathrm{CO}_{2}$ and $\mathrm{CH}_{4}$ using an incubation method. The experimental results are displayed in the table "Incubation" (a data subset is published by Fiedler et al. 2017). Besides experimental field and laboratory data sets, different modelled measures of nitrate-leaching are stored in the database. All modelled data originate from empirical modelling of soil water and nitrogen dynamics.

3.3.2 Gas emission data: The tables contain either raw data of gas flux measurements (e.g. the tables "CO2_conc" and "N2O_CH4_CO2_conc") or processed data (e.g. "N2O_CH4_flux"). Different procedures were conducted to calculate gas fluxes. For the OSR project, more details about the $\mathrm{N}_{2} \mathrm{O}$ flux calculation are provided by Ruser et al. 2017. Further information is also given in the metadata table "Methods_". Due to different calculation procedures, four different statistical tables are stored. The table "N2O_CH4_flux" displays two statistical indexes. "Stat_N2O_ID" is used for the OSR project and links all fluxes with the associated statistical measures from the flux calculation in table "Statistics_N2O_flux". For the BGD project, the $\mathrm{N}_{2} \mathrm{O}$ and $\mathrm{CH}_{4}$ fluxes (table "N2O_CH4_flux") and $\mathrm{CO}_{2}$ fluxes (table "CŌ2_flux") are based on weighted linear regressions. Both tables store indexes linking all statistical parameters of the regression procedure. A further statistic table was created for various information on calculated C balance parameters. A link to the table "Balances" is also described by a statistic index. The table "N2O_CH4_daily_flux" contains interpolated and aggregated daily $\mathrm{N}_{2} \mathrm{O}$ and $\mathrm{CH}_{4}$ fluxes.

In addition to field emissions, closed chamber measurements from the Small digestate experiment (BGD project) were used to model $\mathrm{CO}_{2}$ exchange (Reco, NEE and GPP) following a standardized methodology (Hoffmann et al. 2015). The resulting modelled $\mathrm{CO}_{2}$ fluxes are stored in several tables due to the large amount of data. The data subsets are divided by site and treatment of the Small digestate experiment. A campaign index links all parameters to the measured flux values in table "CO2_conc". Model parameters can be based on data from one or several measurement campaigns.

For the OSR project, the closed chamber and the eddy covariance technique were installed in parallel at the Dedelow site and $\mathrm{CO}_{2}$ fluxes were measured during the crop cultivation period of oilseed rape and winter wheat. The measured and modelled $\mathrm{CO}_{2}$ fluxes are stored in the database. A description of the setup, the modelling and a comparison of the $\mathrm{CO}_{2}$ fluxes from the two techniques can be found in Lucas-Moffat et al. (2018).

3.4 METADATA: The metadata tables "Variables", "Units" and "Methods" specify all variables, units and methods used in the GHG-DB-Thuenen. "Variables_info" contains all measured variables used. The variables are explained in a brief description, complemented by information on value plausibility and reference to time and space. It also defines the data type of each variable (raw, processed or general data). The table "Information" lists descriptive information on all columns of the GHG-DBThuenen, except for the column "Variable_". Further metadata tables provide information about sites, experiments, soil profiles, sensor installations, site-specific fertilizations and limits of quantification.

4 SUMMARY: GHG-DB-Thuenen provides greenhouse gas emissions (GHG), as well as other gaseous emissions and agronomic variables were measured for three years $(2011 / 2012-2014 / 2015)$ at eight experimental field sites in Germany. In total 43 million records are stored and archived to quantify and to evaluate greenhouse gas emissions (GHG) for oilseed rape, maize and other energy crops. In January 2021 the database will become publicly available at the OpenAgrar repository OpenAgrar (doi: 10.3220/DATA20180201-080050).

5 ACKNOWLEDGEMENTS: We give special thanks to all others who contributed to the database: Madlen Pohl, Monique Andres, Nicole Jurisch, Johannes Hufnagel, Claudia Bethwell (Leibniz Centre for Agricultural Landscape Research or ZALF, Muencheberg, Germany); Karl-Hermann Mühling, Marcus Rohwer, Achim Seidel (Institute of Crop Science and Plant Breeding, Christian-AlbrechtsUniversity, Kiel, Germany); Sebastian Fiedler, Gerald Jurasinki (Landscape Ecology, Faculty of 
Agricultural and Environmental Sciences, University of Rostock, Germany); Matthias Drösler, Gawan Heintze (Department of Vegetation Ecology; Weihenstephan-Triesdorf, University of Applied Science, Germany).

This database was funded by the Agency for Renewable Resources (FNR) e.V. and the Federal Ministry for Food and Agriculture (BMEL) under funding identification number 22403212 (OSR project) and 22021008 (BGD project).

\section{REFERENCES}

De Klein, C. \& Harvey, M., 2015. "Nitrous oxide chamber methodology guidelines version 1.1" Available at: http://www.globalresearchalliance.org

Fiedler, S., Buczko, U., Jurasinski, G. and Glatzel, S. 2015. "Soil respiration after tillage under different fertiliser treatments - implications for modeling and balancing." Soil \& Tillage Research 150:3042. doi: $10.1016 /$ i.still.2014.12.015

Fiedler, S. R., Leinweber, P., Jurasinski, G., Eckhardt, K.-U. and Glatzel, S. 2016. "Tillage-induced short-term soil organic matter turnover and respiration." SOIL 2:475-486. doi: 10.5194/soil-2-475$\underline{2016}$

Fiedler, S. R., Augustin, J., Wrage-Mönnig, N., Jurasinski, G., Gusovius, B. and Glatzel, S. 2017. "Potential short-term losses of $\mathrm{N}_{2} \mathrm{O}$ and $\mathrm{N}_{2}$ from high concentrations of biogas digestate in arable soils." SOIL 3(3):161-176. doi: 10.5194/soil-3-161-2017

Fiedler, S. R., Augustin, J., Wrage-Mönnig, N., Jurasinski, G., Gusovius, B. and Glatzel, S. 2017. Under revision. " $\mathrm{N}_{2} \mathrm{O}$ and $\mathrm{N}_{2}$ losses from simulated injection of biogas digestate depend mainly on soil texture, moisture and temperature." SOIL. doi: 10.5194/soil-2017-6

Flessa, H., Fuß, R., Andres, M., Augustin, J., Christen, O., Dittert, K., Hegewald, H., Heilmann, H., Huth, V., Kage, H., Kern, J., Kesenheimer, K., Knieß, A., Köbke, S., Lewandowski, I., Mallast, J., Moffat, A., Mühling, K.H., Öhlschläger, G., Pahlmann, I., Prochnow, A., Räbiger, T., Ruser, R., Stichnothe, H., Suárez-Quiñones, T., Weiser, C. 2017, "Minderung von Treibhausgasemissionen im Rapsanbau unter besonderer Berücksichtigung der Stickstoffdüngung" - OSR final report (in German), Thuenen Institute of Climate-Smart Agriculture. url: http://www.fnrserver.de/ftp/pdf/berichte/22403212.pdf

Hagemann, U., Augustin, J., Prescher, A., Kage, H., Glatzel, S., Jurasinski, G., Mühling, K. H., Stichnothe, H., Drösler, M., Bethwell, C., Knieß, A., Neukam, D. 2016, "Potenziale zur Minderung der Freisetzung von klimarelevanten Spurengasen beim Anbau von Energiepflanzen zur Gewinnung von Biogas“ - BGD final report (in German), Leibniz Centre for Agricultural Landscape Research. url: http://www.fnr-server.de/ftp/pdf/berichte/22021008.pdf

Heintze, G., Eickenscheidt, T., Schmidhalter, U. and Drösler, M. 2017. "Influence of Soil Organic Carbon on Greenhouse Gas Emission Potential After Application of Biogas Residues or Cattle Slurry: Results from a Pot Experiment." Pedosphere 27(5): 807-821. doi: 10.1016/S1002$\underline{0160(17) 60388-6}$

Hoffmann, M., Jurisch, N., Albiac Borraz, E., Hagemann, U., Drösler, M., Sommer, M. and Augustin, J. 2015. "Automated modeling of ecosystem $\mathrm{CO}_{2}$ fluxes based on periodic closed chamber measurements: A standardized conceptual and practical approach." Agricultural and Forest Meteorology 200:30-45. doi: 10.1016/i.agrformet.2014.09.005

Hoffmann, M., Pohl, M., Jurisch, N., Prescher, A.-K., Mendez Campa, E., Hagemann, U., Remus, R., Verch, G., Sommer, M. and Augustin, J. 2018. Maize carbon dynamics are driven by soil erosion state and plant phenology rather than nitrogen fertilization form. Soil \& Tillage Research 175:255266. doi: $10.1016 /$ j.still.2017.09.004

Hutchinson, G. L. and Mosier, A. R. 1981. Improved soil cover method for field measurement of nitrous oxide fluxes. SSSAJ 45(2):311-316. doi: 10.2136/sssaj1981.03615995004500020017x

Huth, V., Vaidya, S., Hoffmann, M., Jurisch, N., Günther, A., Gundlach, L., Hagemann, U., Elsgaard, L. and Augustin, J. 2017. "Divergent NEE balances from manual-chamber $\mathrm{CO}_{2}$ fluxes linked to different measurement and gap-filling strategies: A source for uncertainty of estimated terrestrial C sources and sinks?" Journal of Plant Nutrition and Soil Science 180(3):302-315. doi: 10.1002/jpln.201600493

Mallast, J., Stichnothe, H., Flessa, H., Fuß, R., Lucas-Moffat, A. M., Petersen-Schlapkohl, U., Augustin, J., Hagemann, U., Kesenheimer, K., Ruser, R., Quiñones, T. S., Prochnow, A., Dittert, K., Huth, V. and Glatzel, S. 2018. "GHG-DB-Thuenen - Multi-variable experimental data set of agronomic data and gaseous soil emissions of energy crop cultivation at eight sites in Germany." OpenAgrar. doi: 10.3220/DATA20180201-080050 
Lucas-Moffat, A. M., Huth, V., Augustin, J., Brümmer, C., Herbst, M. and Kutsch, W. L. "Towards pairing plot and field scale measurements in managed ecosystems: Using eddy covariance to crossvalidate $\mathrm{CO}_{2}$ fluxes modeled from manual chamber campaigns." Agricultural and Forest Meteorology 256-257:362-378. doi: 10.1016/j.agrformet.2018.01.023

Pacholski, A., Cai, G., Nieder, R., Richter, J., Fan, X., Zhu, Z. and Roelcke, M. 2006. "Calibration of a simple method for determining ammonia volatilization in the field - comparative measurements in Henan Province, China." Nutrient Cycling in Agroecosystems 74(3):259-273. doi: 10.1007/s10705-006-9003-4

Parkin, T.B. and Venterea, R. T. 2010. "Sampling protocols. Chapter 3. Chamber-based trace gas flux measurements." In: Sampling protocols. R.F. Follett, editor. Pp.3-1 to 3-39. Available at: www.ars.usda.gov/research/GRACEnet

Peter, C., Fiore, A., Hagemann, U., Nendel, C., and Xiloyannis, C. 2016. "Improving the accounting of field emissions in the carbon footprint of agricultural products: a comparison of default IPCC methods with readily available medium-effort modeling approaches." The International Journal of Life Cycle Assessment 21(6):791-805. doi: 10.1007/s11367-016-1056-2

Pohl, M., Hoffmann, M., Hagemann, U., Giebels, M., Albiac-Borraz, E., Sommer, M., and Augustin, J. 2015. "Dynamic $C$ and $N$ stocks - key factors controlling the $C$ gas exchange of maize in a heterogenous peatland." Biogeosciences 12:2737-2752. doi: 10.5194/bg-12-2737-2015

Ruser, R., Fuß, R., Andres, M., Hegewald, H., Kesenheimer, K., Köbke, S., Räbiger, T., Suarez Quinones, T., Augustin, J., Christen, O., Dittert, K., Kage, H., Lewandowski, I., Prochnow, A., Stichnothe, H. and Flessa, H. 2017. „Nitrous oxide emissions from winter oilseed rape cultivation.” Agriculture, Ecosystems and Environment 249:57-69. doi: 10.1016/j.agee.2017.07.039. 